\title{
Dynamic Modes of Synchronous Electric Drive with Centrifugal Hydraulic Load of Pump Station
}

\author{
Vladyslav Lysiak*, Mykhailo Oliinyk \\ Lviv Polytechnic National University, 12 Bandera Street, Lviv, 79013, Ukraine
}

Received: January 29, 2021. Revised: February 18, 2021. Accepted: February 25, 2021.

(c) 2021 Authors. Published by Lviv Polytechnic National University.

\begin{abstract}
The contemporary state of the modelling of the pump station's electric drive in a complex with its centrifugal hydraulic load has been analysed. It was found that most studies focus either on the modelling and development of automatic control systems for the asynchronous electric drive of pumps or on the optimization of performance indicators of the station as a whole. Besides, usually only one of the subsystems of a pumping station (or an electrically-operated pump unit) is modelled with a good degree of detail: either electromagnetic or hydraulic. This approach does not allow a concurrent research of electromagnetic and hydraulic processes in them. The paper proposes a comprehensive mathematical model of the dynamic modes of the synchronous electrically-operated centrifugal pump unit with a pipeline, in which the electromagnetic and hydraulic subsystems are presented with a balanced degree of detail. The developed model was verified and its viable applications were suggested.
\end{abstract}

Keywords: synchronous motor; pumping station; centrifugal pump; pipeline; model.

\section{Definition of the research problem selected for the study}

One of the largest consumers of electrical power is high-power pumping stations (PS). Depending on the purpose and current conditions, the modes of their operation can be both quasi steady-state (normal operation modes of major pipelines and large distribution pipelines (PL) with a low speed of fluid flow variation [1]) and fast changing (emergency modes, scheduled start-stop operations). Electromechanical transients in any assemblies are accompanied with manifold surges of electricity consumption as compared to normal operation modes, as well as with a higher risk of equipment failures. As high-power PSs are of strategic importance, these circumstances impose certain restrictions on the possibility of conducting physical experiments.

\section{Analysis of the recent studies and publications on the problem}

Despite the substantial benefits offered by the use of synchronous motors (SM) in comparison with induction motors for driving centrifugal pumps (CP) [2], [3], these are the synchronous sets of high-powered PS that, we believe, have not received sufficient research attention. The following major areas of modern studies of this problem can be distinguished: modelling of dynamic modes of controlled synchronous electric drives of low- and mediumpower fluid pumping systems with utterly simplified representation of the hydraulic subsystem (as in [4]-[8]), modelling of steady-state modes ([3], [9]) and obtaining of generalized energy indicators and technical-and-economic indicators ([10]). Therefore, the study of high-powered fluid pumping systems with the synchronous electric drive is of topical importance.

\footnotetext{
${ }^{*}$ Corresponding author. Email address: vladyslav.h.lysiak@lpnu.ua
}

This paper should be cited as: V. Lysiak, M. Oliinyk. Dynamic modes of synchronous electric drive with centrifugal hydraulic load of pump station. Energy Engineering and Control Systems, 2021, Vol. 7, No. 1, pp. 48 - 55. https://doi.org/10.23939/jeecs2021.01.048 


\section{Aim of the research}

The study aims at developing a mathematical model of the dynamic modes of the synchronous electric drive with a centrifugal hydraulic load of the pumping station (SECPS) with a balanced degree of detail of the electromagnetic and hydraulic subsystems with an option for studying the processes occurring in these subsystems as a whole and the processes in their separate structural elements.

\section{Results and their discussion}

In order to build a mathematical model of SECPS, let us consider its separate elements. The equations will be written in relative units using the system of base values characteristic for a specific element.

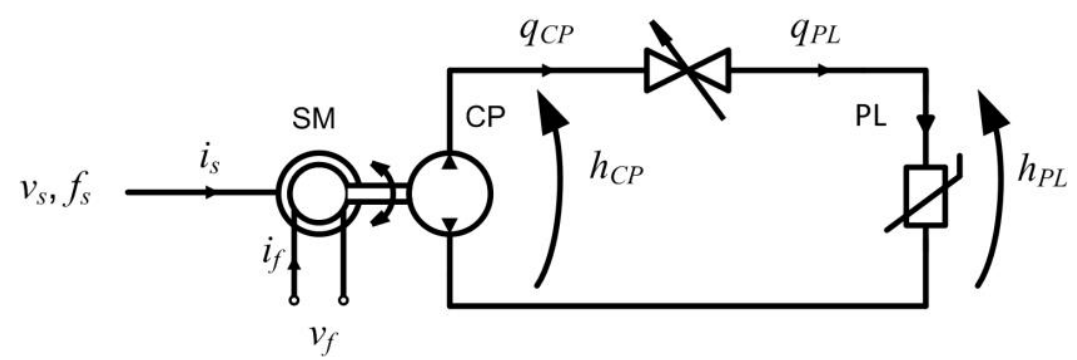

Fig.1. Block diagram of SECPS

Synchronous electric drive (electromagnetic subsystem). The equation of the mathematical model (MM) of the synchronous motor are written based on the generalized equations of the synchronous machine with the following assumptions: the temperature mode is steady-state, the windings have lumped parameters, the flux-current curve of the magnetic system is non-linear, the effect of the core shape on the magnetic field distribution is disregarded, the operation mode is symmetrical. The equations are formulated in the orthogonal $d-q$ coordinates rigidly bound with the rotor in relative units (RU) using the following system of major base values: $\omega_{\text {sm.b }}=\omega_{\text {sm.syn }}=\omega_{\text {sm.nom }} ; V_{\text {sm.b }}=\sqrt{2 / 3} V_{\text {sm.nom }}$; $T_{\text {sm.b }}=S_{\text {sm.b }} / \omega_{\text {sm.b }}=P_{\text {sm.nom }} /\left(\eta_{\text {sm.nom }} \cos \varphi_{\text {sm.nom }} \omega_{\text {sm.nom }}\right) ; Z_{\text {sm.b }}=V_{s m . b} / I_{\text {sm.b }}=V_{\text {sm.nom }}^{2} \eta_{\text {m.nom }} \cos \varphi_{\text {sm.nom }} \times, \times \omega_{\text {sm.nom }} / P_{\text {sm.nom }}$, where $\omega_{\text {sm.nom }}, V_{\text {sm.nom }}, P_{\text {sm.nom }}, \eta_{\text {sm.nom }}, \cos \varphi_{\text {sm.nom }}$ are nominal SM datasheet parameters. The SM model with $n$ damping circuits presented in [11] was taken as the basis. It features taking into account the non-linearity of its main magnetic circuit in the form of a non-linear magnetic resistance dependent on the flux linkage:

$$
\begin{gathered}
R_{s} i_{s d}+L_{s} \frac{d i_{s d}}{d t}+\frac{d \psi_{\delta d}}{d t}-\omega_{r}\left(L_{s} i_{s q}+\psi_{\delta q}\right)=v_{s d} \\
R_{s} i_{s q}+L_{s} \frac{d i_{s q}}{d t}+\frac{d \psi_{\delta q}}{d t}+\omega_{r}\left(L_{s} i_{s d}+\psi_{\delta d}\right)=v_{s q} \\
R_{f} i_{f d}+L_{f} \frac{d i_{f d}}{d t}+\frac{d \psi_{\delta d}}{d t}=v_{f d} ; \\
R_{f} i_{f q}+L_{f} \frac{d i_{f q}}{d t}+\frac{d \psi_{\delta q}}{d t}=v_{f q} \\
R_{n} i_{n q}+L_{n} \frac{d i_{n q}}{d t}+\frac{d \psi_{\delta q}}{d t}=0 \\
R_{n} i_{n q}+L_{n} \frac{d i_{n q}}{d t}+\frac{d \psi_{\delta q}}{d t}=0 \\
i_{s d}+i_{f d}+\sum_{n} i_{n d}-R_{m}\left(\psi_{\delta d}, \psi_{\delta q}\right) \psi_{\delta d}+\frac{1}{R_{a}} \omega_{r} \psi_{\delta q}=0
\end{gathered}
$$




$$
\begin{gathered}
i_{s q}+i_{f q}+\sum_{n} i_{n q}-R_{m}\left(\psi_{\delta d}, \psi_{\delta q}\right) \psi_{\delta q}-\frac{1}{R_{a}} \omega_{r} \psi_{\delta d}=0 ; \\
J_{\Sigma} \omega_{s m . b} \frac{d \omega_{r}}{d t}=T_{s m . b} T_{e}-T_{c p . b} T_{m},
\end{gathered}
$$

where $\omega_{r}$ is the rotation frequency of the rotor; $\psi_{\delta d, q}$ are orthogonal components of the flux linkage from the magnetic flux of the air gap reduced to the stator winding; $R_{a}$ is the equivalent resistance, which takes into account active power losses in the steel core; $T_{e}=\psi_{\delta d} i_{s q}-\psi_{\delta q} i_{s d}, T_{m}$ is the electromagnetic torque of the motor and the operating mechanism torque, respectively; $J_{\Sigma}$ is the total moment of inertia of the synchronous electrically-operated pump unit, $\mathrm{kg} \cdot \mathrm{m}^{2}$; for the corresponding windings: $R_{s}, L_{s}, R_{f}, L_{f}, R_{n}, L_{n}$ are the parameters; $i_{s d, q}, i_{f d, q}, i_{n d, q}$ are orthogonal components of currents; $v_{s d, q}, v_{f d, q}$ are orthogonal components of voltages. The non-linear static magnetic resistance of the main magnetic circuit of SM is approximated by the polynomial based on [12]: $R_{m}\left(\psi_{\delta d}, \psi_{\delta q}\right)=I_{m u}\left(a_{0}+a_{2}\left(\psi_{\delta d}^{2}+\psi_{\delta q}^{2}\right)+a_{4}\left(\psi_{\delta d}^{2}+\psi_{\delta q}^{2}\right)^{4}\right)$, where $\mathrm{a}_{0}=0.82 ; \mathrm{a}_{2}=0.148 ; \mathrm{a}_{4}=0.044 ; I_{m n}=1 /\left(x_{\sigma}+x_{\mathrm{a}}\right)$, where $x_{\sigma}, x_{\mathrm{a}}$ are relative leakage and magnetizing inductances of SM in the nominal mode. It should be noted that according to [13], the effect of the frequency on this parameter becomes significant for the frequency values over $100 \mathrm{~Hz}$. Therefore, in this case we disregard this effect. Besides, further on, the orthogonal components of the stator voltage will be expressed through its amplitude value $U_{s}$ and angle $\delta$ of the rotor pole shift with respect to the stator pole:

$$
v_{s d}=V_{s} \sin \delta ; v_{s q}=-V_{s} \cos \delta .
$$

The operating mechanism torque $T_{m}$ (the $\mathrm{CP}$ torque taking into consideration the power losses on the friction in the bearings and on the ventilation) is modelled based on the following assumptions: the temperature mode is steadystate, the CP impeller, SM rotor and their common shaft are considered to be absolutely rigid. The base SM frequency $\omega_{b}=\omega_{s m . b}=\omega_{s m . s y n}$ is taken as the common base value of the frequency of both subsystems.

$$
T_{m}=T_{c p}+\Delta T_{m},
$$

where $T_{c p}=h_{0} q_{\Sigma} \omega_{c p . b} /\left(\omega_{b} \omega_{r}\right)$, where $h_{0}, q_{\Sigma}$ are the fictitious head and total flow of the idealized CP [14], [15]; $\Delta T_{\mathrm{m}}=\Delta T_{0} \omega_{\mathrm{r}}^{2}$ (if other data is unavailable, we assume $\Delta T_{0}=0.02$ ).

Hydraulic load (hydraulic subsystem). The mathematical model of CP with a pipeline presented in [16] based on [14], [15] was taken as the base according to the principle of electrohydraulic analogy, considering the following assumptions: the temperature mode is steady-state, and the hydraulic fluid is uncompressible and homogeneous. This model makes it possible to study the dynamic modes both of $\mathrm{CP}$ as a whole and of its internal elements, taking into consideration the influence of the pumping modes and physical properties of the fluid. The latter indirectly accounts for the effect of the fluid temperature and pumping modes, as the fluid temperature has a strong impact on the fluid's kinematic viscosity. The equations are formulated in the orthogonal $d-q$ coordinates in RU rigidly bound with the impeller, using the following system of main base values: $\omega_{c p . b}=\omega_{c p . n o m} ; H_{c p . b}=H_{c p . n o m} ; \quad Q_{c p . b}=Q_{c p . n o m}$; $T_{c p . b}=S_{c p . b} / \omega_{c p . b}=\rho g H_{s c . b} Q_{s c p . b} / \omega_{c p h b} ; \quad Z_{p . b}=\rho g H_{c p . b} / Q_{c p . b}$, where $\omega_{c p . n o m}, H_{c p . n o m}, Q_{c p . n o m}$ are the CP nominal datasheet parameters; $\rho, \mathrm{g}$ are the fluid density and free fall acceleration.

Mathematical models of SECPS. In order to adapt the SECPS mathematical model for the use in computer math systems, let us change it for it to assume its final form by solving the SM model equations (1)-(9), taking into account (10), (11) with respect to the first-order derivative, and by supplying them with the CP model equations. As a result, we finally obtain:

$$
\frac{d i_{s d}}{d t}=-\frac{R_{s}}{L_{s}} i_{s d}+\omega_{r} i_{s q}+\frac{1}{L_{s}} \omega_{r} \psi_{\delta q}-\frac{1}{L_{s}} e_{\delta d}+\frac{1}{L_{s}} v_{s} \sin \delta
$$




$$
\begin{aligned}
& \frac{d i_{s q}}{d t}=-\frac{R_{s}}{L_{s}} i_{s q}-\omega_{r} i_{s d}-\frac{1}{L_{s}} \omega_{r} \psi_{\delta d}-\frac{1}{L_{s}} e_{\delta q}-\frac{1}{L_{s}} v_{s} \cos \delta ; \\
& \frac{d i_{f d}}{d t}=-\frac{R_{f}}{L_{f}} i_{f d}-\frac{1}{L_{f}} e_{\delta d}+\frac{1}{L_{s}} v_{f d} \\
& \frac{d i_{f q}}{d t}=-\frac{R_{f}}{L_{f}} i_{f q}-\frac{1}{L_{f}} e_{\delta q}+\frac{1}{L_{s}} v_{f q} ; \\
& \frac{d i_{1 d}}{d t}=-\frac{R_{1}}{L_{1}} i_{1 d}-\frac{1}{L_{1}} e_{\delta d} \\
& \frac{d i_{1 q}}{d t}=-\frac{R_{1}}{L_{1}} i_{1 q}-\frac{1}{L_{1}} e_{\delta q} ; \\
& \frac{d \psi_{\delta d}}{d t}=e_{\delta d} \\
& \frac{d \psi_{\delta q}}{d t}=e_{\delta d} \\
& i_{s d}+i_{f d}+i_{1 d}-R_{m}\left(\psi_{\delta d}, \psi_{\delta q}\right) \psi_{\delta d}+\frac{1}{R_{a}} \omega_{r} \psi_{\delta q}=0 ; \\
& i_{s q}+i_{f q}+i_{1 q}-R_{m}\left(\psi_{\delta d}, \psi_{\delta q}\right) \psi_{\delta q}-\frac{1}{R_{a}} \omega_{r} \psi_{\delta \delta}=0 \\
& \frac{d \delta}{d t}=1-\frac{1}{\omega_{s}} \omega_{r} \\
& \frac{d \omega_{r}}{d t}=\frac{1}{J_{\Sigma} \omega_{b}}\left(T_{s m . b}\left(\psi_{\delta d} i_{s q}-\psi_{\delta q} i_{s d}\right)-T_{c p . b} H_{0 . n o m} \omega_{r} \frac{\omega_{b}}{\omega_{c p . b}} \sqrt{\left(q_{11 d}+q_{44 d}\right)^{2}+\left(q_{11 q}+q_{44 q}\right)^{2}}-\Delta T_{m 0} \omega_{r}^{2}\right) ; \\
& \frac{d \dot{q}_{11}}{d t}=a_{11} \dot{q}_{11}+a_{12} \dot{q}_{22}+a_{13} \dot{q}_{33}+b_{1} \dot{h}_{0} \\
& \frac{d \dot{q}_{22}}{d t}=a_{21} \dot{q}_{11}+a_{22} \dot{q}_{22}+a_{23} \dot{q}_{33}+b_{2} \dot{h}_{0} \\
& \frac{d \dot{q_{33}}}{d t}=a_{31} \dot{q}_{11}+a_{32} \dot{q}_{22}+a_{33} \dot{q}_{33}+b_{3} \dot{h}_{0} \\
& \frac{d \dot{q}_{44}}{d t}=a_{44}\left(q_{L}\right) \dot{q}_{44}+b_{4} \dot{h}_{0}
\end{aligned}
$$




$$
\begin{gathered}
h_{L d} q_{33 q}-h_{L q} q_{33 d}=0 \\
\frac{d q_{L}}{d t}=c_{1} q_{L}+c_{2} \sqrt{h_{L d}^{2}+h_{L q}^{2}}+c_{3} h_{s t}
\end{gathered}
$$

where $t$ is the time; $\omega_{s}$ is the rotation frequency of the SM stator winding voltage; $e_{\delta d, q}$ are the orthogonal components of the total emf from the magnetic field of the air gap; $h_{L}=\sqrt{h_{L d}^{2}+h_{L q}^{2}}, \quad q_{L}=\sqrt{q_{33 d}^{2}+q_{33 q}^{2}}, \quad h_{s t}$ are the actual values of the fluid head and flow at the CP output and also of the PL static counter head; $r_{L}, L_{L}$ are the equivalent dissipative hydraulic resistance and hydraulic inductance of PL; $\dot{q}_{11}=q_{11 d}+j q_{11 q}, \quad \dot{q}_{22}=q_{22 d}+j q_{22 q}, \quad \dot{q}_{33}=q_{33 d}+j q_{33 q}$, $\dot{q}_{44}=q_{44 d}+j q_{44 q}$ are complex flows of the equivalent circuit [16] of $\mathrm{CP} ; \quad \dot{q}_{\Sigma}=\dot{q}_{11}+\dot{q}_{44}$, $\dot{h}_{0}=\omega_{r}^{2} H_{0 . \text { nom }}\left(\omega_{b} / \omega_{c p . b}\right)^{2}\left(\cos \left(\omega_{r} \omega_{b} t+\Psi_{0 c p}\right)+j \sin \left(\omega_{r} \omega_{b} t+\Psi_{0 c p}\right)\right)$ are complex fictitious heads ( $H_{0 . n o m}$ is the nominal value, $\Psi_{0 c p}$ is an arbitrary value) and flow of the idealized CP; $a_{11}=\frac{r_{11}}{L_{11}^{\prime}}-\frac{r_{21}}{L_{12}^{\prime}} ; a_{12}=\frac{r_{22}}{L_{12}^{\prime}}-\frac{r_{32}}{L_{13}^{\prime}}$; $a_{13}=\frac{r_{33}}{L_{13}^{\prime}}-\frac{r_{23}}{L_{12}^{\prime}} ; \quad a_{21}=\frac{r_{11}}{L_{21}^{\prime}}-\frac{r_{21}}{L_{22}^{\prime}} ; \quad a_{22}=\frac{r_{22}}{L_{22}^{\prime}}-\frac{r_{32}}{L_{23}^{\prime}} ; \quad a_{23}=\frac{r_{33}}{L_{23}^{\prime}}-\frac{r_{23}}{L_{22}^{\prime}} ; \quad a_{31}=\frac{r_{11}}{L_{31}^{\prime}}-\frac{r_{21}}{L_{32}^{\prime}} ; \quad a_{32}=\frac{r_{22}}{L_{32}^{\prime}}-\frac{r_{32}}{L_{33}^{\prime}} ;$ $a_{33}=\frac{r_{33}}{L_{33}^{\prime}}-\frac{r_{23}}{L_{32}^{\prime}} ; \quad a_{44}(t)=-\frac{r_{\text {mech }}\left(q_{L}\right)}{L_{\text {mech }}} ; \quad c_{1}=-\frac{r_{L}}{L_{L}} ; \quad c_{2}=\frac{1}{L_{L}} ; \quad c_{3}=-\frac{1}{L_{L}} ; \quad b_{1}=-\frac{1}{L_{11}^{\prime}} ; \quad b_{2}=-\frac{1}{L_{21}^{\prime}} ; \quad b_{3}=-\frac{1}{L_{31}^{\prime}} ;$ $b_{4}=\frac{1}{L_{\text {mech }}}$, де $\quad r_{11}=r_{12}=R_{\mu Q . n o m} ; \quad r_{22}=r_{23}=R_{\Delta Q . n o m} ; \quad r_{33}=R_{\Delta Q . n o m}+R_{\Delta H . n o m} ; \quad L_{11}=L_{t . n o m}+L_{\mu H . n o m}+L_{\mu Q . n o m} ; \quad L_{12}=L_{21}=L_{\mu Q . n o m} ;$ $L_{23}=L_{32}=L_{\Delta Q . n o m} ; \quad L_{33}=L_{\Delta Q . n o m}+L_{\Delta H . n o m} ; \quad L_{22}=L_{\mu Q . n o m}+L_{\Delta Q . n o m}, \quad$ where $\quad L_{11}^{\prime}=\left(\frac{L_{12} L_{21}}{L_{11}^{2} L^{\prime \prime}}-\frac{1}{L_{11}}\right)^{-1} ; \quad L_{22}^{\prime}=L^{\prime \prime} ;$ $L_{33}^{\prime}=\left(\frac{L_{32} L_{23}}{L_{33}^{2} L^{\prime \prime}}-\frac{1}{L_{33}}\right)^{-1} ; L_{12}^{\prime}=L_{21}^{\prime}=\frac{L_{11} L^{\prime \prime}}{L_{12}} ; L_{13}^{\prime}=L_{31}^{\prime}=\frac{L_{11} L_{33} L^{\prime \prime}}{L_{12} L_{23}} ; L_{23}^{\prime}=L_{32}^{\prime}=\frac{L_{33} L^{\prime \prime}}{L_{23}}$, where $L^{\prime \prime}=\frac{L_{12} L_{21}}{L_{11}}-L_{22}+\frac{L_{23} L_{32}}{L_{33}}$.

It is worth reminding that in all the presented expressions there are relative values of the parameters except for the total moment of inertia $J_{\Sigma}, \mathrm{kg} \cdot \mathrm{m}^{2}$. The algorithms of calculating the dissipative hydraulic resistances $R_{\mu Q . n o m}$, $R_{\Delta \text { Q.nom }}, R_{\Delta \text {.nom }}$ dependent on the kinematic viscosity and density of the fluid, the non-linear dissipative resistance $r_{\text {mech }}$ dependent on the pumping mode as well as that for the hydraulic inductances $L_{\mu H . n o m}, L_{\mu Q . n o m}, L_{\Delta Q . n o m}, L_{\Delta H . n o m}$, $L_{\text {mech }}$ are presented in [14].

The viability of the model was verified by its implementing in Mathcad. For the test simulations of the dynamic modes, there were selected 14NDs-N CP driven by the synchronous motor SD2-74/25-6U3 $\left(R_{s^{*}}=0.021344\right.$, $\left.L_{s^{*}}=0.072, R_{l^{*}}=0.059354, L_{1^{*}}=0.2846, R_{f^{*}}=0.00756, L_{f^{*}}=0.31586, R_{a^{*}}=12.31\right)$. Their parameters are adduced in Tables 1,2 . The total moment of inertia of the system SM-CP, connected by an absolutely rigid shaft is $J_{\Sigma}=94.5 \mathrm{~kg} \cdot \mathrm{m}^{2}$.

Table 1. Parameters of SM SD2-74/25-6U3.

\begin{tabular}{|c|c|c|c|c|c|c|c|c|c|c|c|}
\hline$P_{\text {nom }}, \mathrm{kW}$ & $\eta_{\text {nom, }}$ & $V_{\text {s.nom }}, \mathrm{V}$ & $n_{\text {nom }}, \mathrm{rpm}$ & $\cos \varphi_{\mathrm{nom},}$ & $I_{\text {s.nom }}, \mathrm{A}$ & $T_{m a x^{*}}$ & $T_{s^{*}}$ & $I_{\mathrm{k}^{*}}$ & $V_{f . n o m}, \mathrm{~V}$ & $I_{f . n o m}, \mathrm{~A}$ & $\begin{array}{c}J_{\text {sm }}, \\
\mathrm{kg} \cdot \mathrm{m}^{2}\end{array}$ \\
\hline 280 & 0.943 & 380 & 1000 & 0.9 (lead.) & 501 & 1.7 & 1.2 & 6.3 & 28 & 135 & 84 \\
\hline
\end{tabular}

\begin{tabular}{|c|c|c|c|c|c|c|c|c|c|c|c|c|c|c|}
\hline $\begin{array}{c}H_{\text {nom, }} \\
\mathrm{m}\end{array}$ & $\begin{array}{l}Q_{\text {nom }}, \\
\mathrm{m}^{3} / \mathrm{h}\end{array}$ & $\eta_{\text {nom }}$ & $\begin{array}{l}\mathrm{n}_{\text {nom }}, \\
\mathrm{rpm}\end{array}$ & $\begin{array}{c}P_{\text {hydr } \cdot \text { nom }}, \\
\mathrm{kW}\end{array}$ & $H_{0 . \text { nom* }}$ & $R_{\Delta Q^{*}}$ & $L_{\Delta Q^{*}}$ & $R_{\Delta H^{*}}$ & $L_{\Delta H^{*}}$ & $L_{t^{*}}$ & $L_{\mu H^{*}}$ & $L_{\mu Q^{*}}$ & $R_{m e c h^{*}}$ & $L_{m e c h}{ }^{*}$ \\
\hline 45 & 1260 & 0.809 & 980 & 154 & 1.302 & 29.47 & 9.49 & $6.627 \cdot 10^{-4}$ & 0.4144 & 0.00876 & 0.0352 & 0.2375 & 7.180 & 0.02287 \\
\hline
\end{tabular}

Table 2. Parameters of CP 14NDs-N.

The results of computer simulation in Mathcad are shown in Fig. 2-15. 


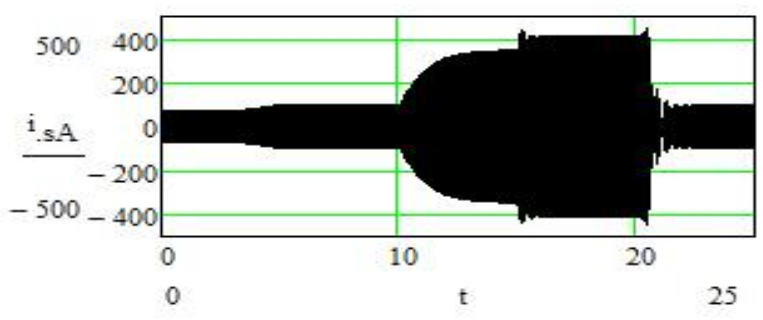

Fig. 2. Phase A current of SM stator

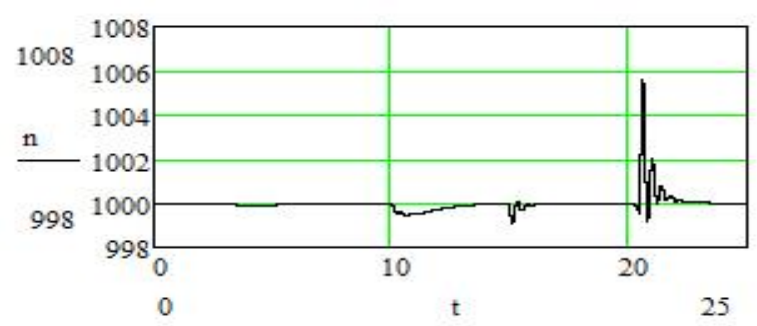

Fig. 4. Rotational speed of SM and CP common shaft

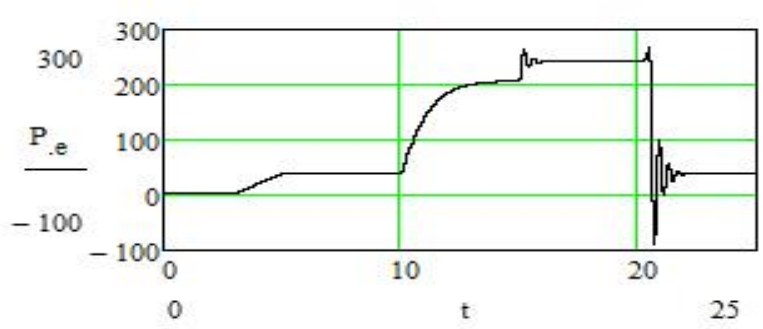

Fig. 6. SM active power

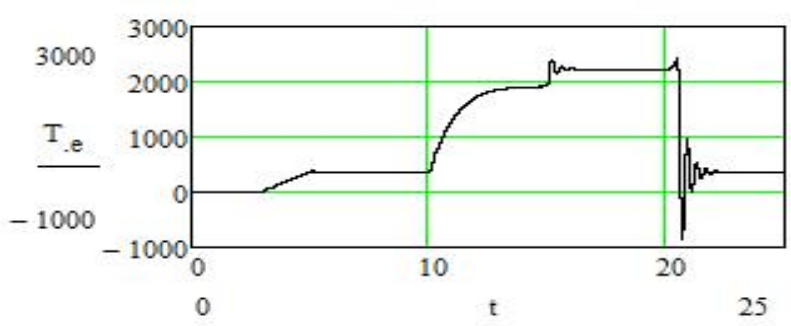

Fig. 8. SM electromagnetic torque

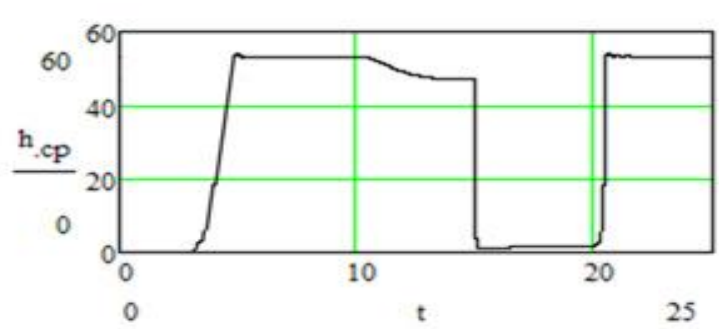

Fig. 10. Fluid head at CP outlet

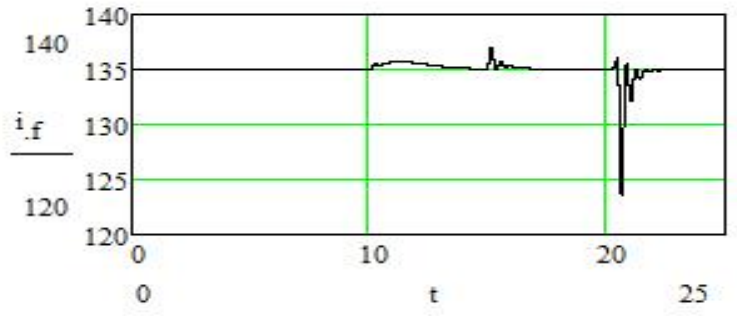

Fig. 3. SM excitation current

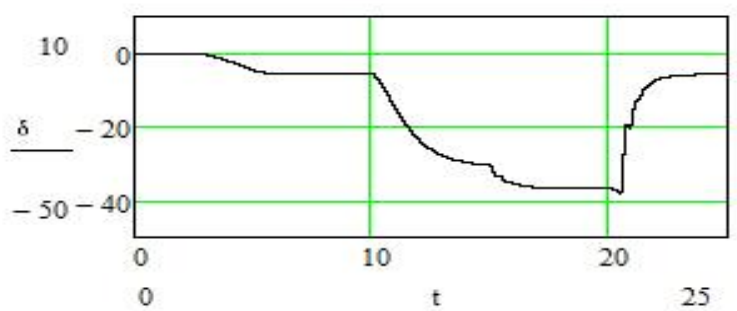

Fig. 5. Angle $\delta$ of the shift of SM rotor and stator poles' axes

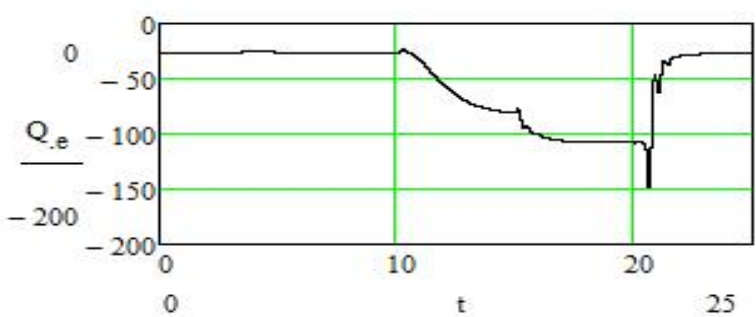

Fig. 7. SM reactive power

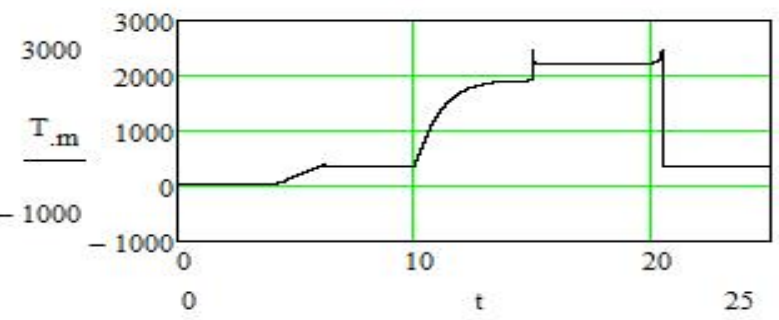

Fig. 9. Torque

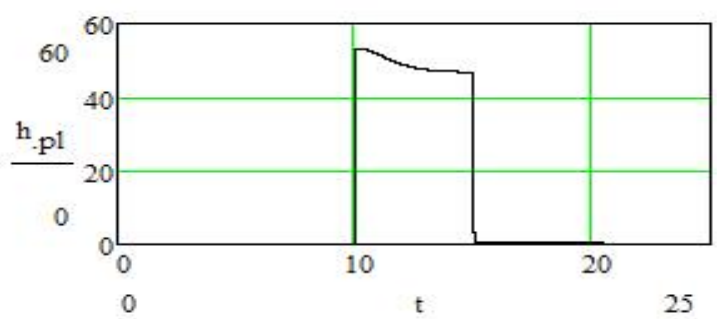

Fig. 11. Fluid heat at PL inlet 


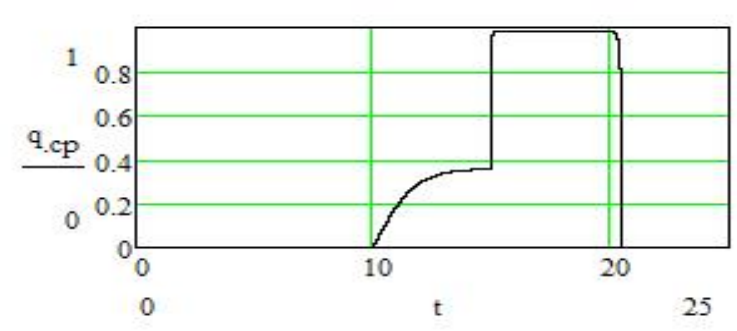

Fig. 12. Fluid flow at $\mathrm{CP}$ outlet

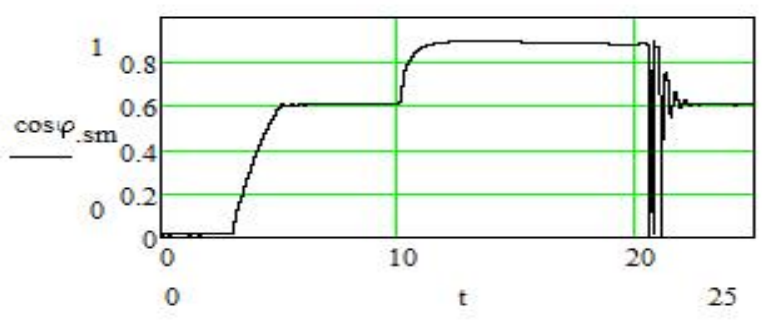

Fig. 14. SM power factor

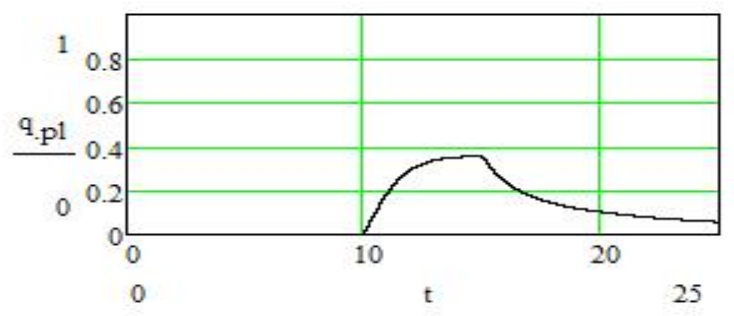

Fig. 13. Fluid flow at PL inlet

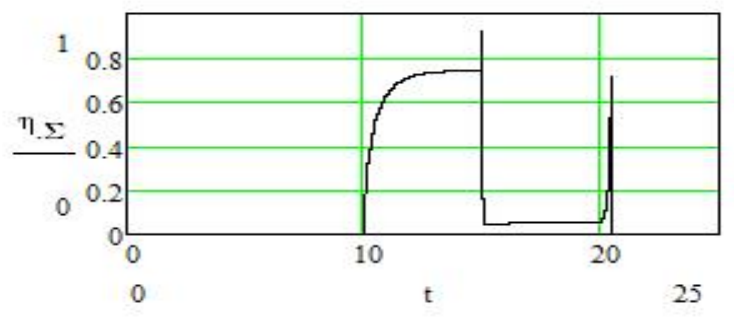

Fig. 15. Total output-input ratio of SECPS

Using the developed model, the sequences of the following operation modes of SECPS were calculated. At first, SM was not loaded, and the CP outlet valve was shut. Then, during the time from $3 \mathrm{~s}$ to $5 \mathrm{~s}$, SM and CP were gradually connected in a linear fashion. At a time of $10 \mathrm{~s}$, during $0.5 \mathrm{~s}$, the valve at the $\mathrm{CP}$ outlet completely opened and the fluid began to flow into PL. At a time of $15 \mathrm{~s}$, during $0.1 \mathrm{~s}$ the complete depressurization of the CP-PL connection occurred; at a time of $20 \mathrm{~s}$, during $0.5 \mathrm{~s}$ the CP outlet valve was completely shut.

\section{Conclusion}

A mathematical model of the dynamic modes of the high-power synchronous electric drive with a centrifugal pumping load taking into consideration the main hydraulic parameters of the pipeline was developed. The balanced degree of detail of the representation of the hydraulic and electromagnetic subsystems enables a concurrent study both of the processes occurring in these subsystems and of the processes taking place in their separate structural elements. The computer simulation results were obtained. The proposed model can be a useful tool for the simulation of operational and emergency modes of operating high-power systems of fluid transportation and their power supply systems without conducting full-scale experiments, as well as for the design of new objects. The results obtained in this study are planned to be used for building a generalized mathematical model of the dynamic modes of a power supply system for a pumping station.

\section{References}

[1] Kutsyk A.S. Mathematical model of the system "frequency-controlled electric drive - pump - water supply network" / A.S. Kutsyk, A. O. Lozynskyi, O. F. Kinchur // Bulletin of the Lviv Polytechnic National University. Series of Electrical Power and Electromechanical Systems,- 2015.- No. 834.- P. 48-55. (in Ukrainian)

[2] Energy efficiency analysis of fixed-speed pump drives with various types of motors / V. Goman, S. Oshurbekov, V. Kazakbaev, V. Prakht, et al. — DOI 10.3390/app9245295 // Applied Sciences (Switzerland). — 2019. — Vol. 24. — Iss. 9. — 5295.

[3] Yaremak I.I. Multi-purpose optimization of the established modes of operation of electric pumping stations of main oil pipelines. PhD Thesys, Ivano-Frankiv. nat. tech. University of Oil and Gas. - Ivano-Frankivsk, 2018. (in Ukrainian)

[4] Chenni, Rachid \& Zarour, L \& Bouzid, A. \& Kerbache, Tahar. (2006). Comparative study of photovoltaic pumping systems using a permanent magnet synchronous motor (PMSM) and an asynchronous motor (ASM). Rev. Energ. Ren. 9. 17-28.

[5] H. Kim, A. Posa, J. Nerg, J. Heikkinen and J. T. Sopanen, Analysis of Electromagnetic Excitations in an Integrated Centrifugal Pump and Permanent Magnet Synchronous Motor, in IEEE Transactions on Energy Conversion, vol. 34, no. 4, pp. 1759-1768, Dec. 2019, doi: 10.1109/TEC.2019.2935785.

[6] Variable Speed Induction Starting Synchronous Motor Driving Centrifugal Pump / Mohamed I. Abdelwanis, Ragab A. El-Sehiemy / Proceedings of the International Conference on Electrical and Computer Engineering (ICECE 2013) Benghazi, Libya, 2013 .https://www.researchgate.net/publication/236626332. 
[7] Bouzeria, Hamza \& Fetha, C. \& Bahi, Tahar \& Abadlia, Issam \& Zakaria, Layate \& Lekhchine, Salima. (2015). Fuzzy Logic Space Vector Direct Torque Control of PMSM for Photovoltaic Water Pumping System. Energy Procedia. 74. 760-771. 10.1016/j.egypro.2015.07.812.

[8] Ibrahim, M.N.; Rezk, H.; Al-Dhaifallah, M.; Sergeant, P. Modelling and Design Methodology of an Improved Performance Photovoltaic Pumping System Employing Ferrite Magnet Synchronous Reluctance Motors. Mathematics 2020,8, 1429. https://doi.org/10.3390/math8091429

[9] Modelling of steady-state modes of the electrical network from the synchronous electric drive of hydraulic loading / V. H. Lysiak, M. Yo. Oliinyk, M. B. Sabat, Y. L. Shelekh // Electrical Power and Electromechanical Systems. — Lviv : Lviv Polytechnic Publishing House, 2019. — Vol 1. - No. 1. - pp. 36-45. (in Ukrainian)

[10] Analysis of efficiency and reliability indicators of the pump set based on a systemic approach / V.S. Kostyshyn, I.I. Yaremak // Rozvidka ta rozrobka naftovykh ta hazovykh rodovyshch. - 2017. - No.1. - pp. 50-60.

[11] Mathematical Modeling and Simulation of Transients in Power Distribution Systems with Valve Devices and Dynamic Loading / P.Gogolyuk, T. Grechyn, A. Ravlyk, I. Grinberg / Proceedings of the IEEE Power Engineering Society General Meeting, Toronto, Ontario, Canada. - 2003.- pp. 1580-1585.

[12] Shelepeten T.M. Calculation of integral parameters of electromagnetic devices with the help of digital models / TM Shelepeten // Technical electrodynamics: special issue for mater. II International Scientific and Technical conf. "Mathematical modelling in electrical engineering and electrodynamics". - K., 1998. - pp. 169-172. (in Ukrainian)

[13] Pustovetov M. Computer modelling of induction motors and transformers. Examples of interaction with power electronic converters / M. Pustovetov, K. Soltus, I. Sinyavsky. - Saarbrücken (Germany): LAP LAMBERT Academic Publishing, 2013. - 199 p. - ISBN-13: 978-3659-40776-5. - ISBN-10: 3659407763.

[14] Kostyshyn, V.S. Modelling of Centrifugal Pumps' Operation Modes Based on Electrohydraulic Analogy : Published Summary of the Thesis for a Doctor of Sciences in Engineering : spec. 05.15.13 Oil and Gas Pipeline, Storage Depots and Plants / Ivano-Frankivsk National Technical University of Oil and Gas. - Ivano-Frankivsk, 2003. - 36 p. (in Ukrainian)

[15] Kostyshyn, Volodymyr \& Yaremak, Iryna \& Kurlyak, P.O.. (2020). Creation of object-oriented model of centrifugal pump on the basis of electro-hydrodynamic analogy method. Scientific Bulletin of National Mining University. 2019, No. 6. 72-79. 10.29202/nvngu/2019-6/11.

[16] V. Lysiak, M. Oliinyk. Modelling of hydraulic load of electric drive in electrical complex of pumping station. Energy Engineering and Control Systems, 2018, Vol. 4, No. 1, pp. 31-36.- doi: $10.23939 /$ jeecs2018.01.031.

\title{
Динамічні режими синхронного електроприводу з відцентровим гідравлічним навантаженням помпової станції
}

\author{
Владислав Лисяк, Михайло Олійник \\ Національний університет «Львівська політехніка», вул. Степана Бандери, 12, Львів, 79013, Україна
}

\begin{abstract}
Анотація
Проведено аналіз сучасного стану моделювання електроприводу помпових станцій у комплексі 3 його відцентровим гідравлічним навантаженням. Виявлено, що переважна більшість досліджень зосереджена або на моделюванні та розробленні автоматичних систем керування асинхронного електроприводу помп, або на оптимізації показників роботи станцій в цілому. Крім того, зазвичай лише одна з підсистем помпової станції (чи електроприводного помпового агрегату) моделюється з достатньою деталізацію: або електромагнітна, або гідравлічна. Такий підхід не дає змоги одночасно досліджувати електромагнітні та гідравлічні процеси, що відбуваються в них. У цій роботі наведено комплексну математичну модель динамічних режимів синхронного електроприводного відцентрового помпового агрегату з трубопроводом, у якій зі збалансованим ступенем деталізації представлено електромагнітну та гідравлічну підсистеми. Здійснено верифікацію розробленої моделі та запропоновано сфери ії застосування.
\end{abstract}

Ключові слова: синхронний двигун; помпова станція; відцентрова помпа; трубопровід; модель. 